\title{
Development of NILs from heterogeneous inbred families for validating the rust resistance QTL in peanut (Arachis hypogaea L.)
}

\author{
Sharanabasappa b. Yeri ${ }^{1}$, Kenta Shirasama ${ }^{2}$, Manish K. Pandey ${ }^{3}, M$. V. C. Gomda ${ }^{4}$, \\ Vanhi Sujar ${ }^{4}$, Manda Shrismathi ${ }^{3}$, Hajisaheb L. Nadaf ${ }^{4}$, Babu N. Motagi ${ }^{4}, S_{\text {. Lingaraju}}$, \\ A. R. S. Bhat ${ }^{6}$, Rajeen K. Varshney ${ }^{3}$, P. U. Krishnaraj ${ }^{1}$ and Ramesh S. Bhat ${ }^{1,7}$
}

${ }^{1}$ Department of Biotechnology, University of Agricultural Sciences, Dharwad, 580 005, India; ${ }^{2}$ Department of Plant Genome Research, Kazusa DNA Research Institute, Chiba, 292-0818, Japan; ${ }^{3}$ Center of Excellence in Genomics (CEG), International Crops Research Institute for the Semi-Arid Tropics (ICRISAT), Hyderabad, 502 324, India; ${ }^{4}$ Department of Genetics and Plant Breeding, University of Agricultural Sciences, Dharwad, 580 005, India; ${ }^{5}$ Department of Plant Pathology, University of Agricultural Sciences, Dharwad, 580 005, India; ${ }^{6}$ Department of Agricultural Statistics, University of Agricultural Sciences, Dharwad, 580 005, India;

${ }^{7}$ Corresponding author, E-mail: bhatramesh12@gmail.com

With 2 figures and 4 tables

Received June 16, 2013/Accepted September 30, 2013

Communicated by W. Link

\begin{abstract}
Heterogeneous inbred families segregating for rust resistance were identified from the two crosses involving susceptible (TAG 24 and TG 26) and resistant (GPBD 4) varieties of peanut. Rust-resistant (less than score 5) and rust-susceptible (more than score 5) plants were identified in each HIF and evaluated under rust epiphytotic conditions. The set of plants belonging to the same HIF, but differing significantly in rust resistance, not in other morphological and productivity traits, was regarded as nearisogenic lines (NILs). Largely, rust-resistant NILs had GPBD 4-type allele, and susceptible NILs carried either TAG 24 or TG 26-type allele at the three SSR loci (IPAHM103, GM1536 and GM2301) linked to a major genomic region governing rust resistance. Comparison of the remaining genomic regions between the NILs originating from each of the HIFs using transposon markers indicated a considerably high similarity of $86.4 \%$ and $83.1 \%$ in TAG $24 \times$ GPPBD 4 and TG $26 \times$ GPBD 4 , respectively. These NILs are useful for fine mapping and expression analysis of rust resistance.
\end{abstract}

Key words: background markers - genome similarity heterogeneous inbred families - near-isogenic lines — peanut — rust resistance — rust-resistance-linked markers

Peanut (Arachis hypogaea L.) is an important oilseed crop grown and consumed worldwide. Rust disease caused by Puccinia arachidis is one of the devastating foliar disease resulting in severe yield loss and deterioration of fodder quality. Although chemical control of this disease is available, its use is limited by the high cost in addition to not being an eco-friendly approach. Significant progress has been made in developing resistant cultivars through conventional breeding approaches, but combining higher level of resistance with acceptable market traits into highyielding cultivars has not been very successful owing to the factors such as interference among the foliar diseases, complex inheritance pattern (Bromfield and Bailey 1972, Tiwari et al. 1984, Paramasivam et al. 1990) and undesirable linkages of resistance with other traits (Subrahamanyam et al. 1993). Thus, integration of genomic tools with conventional breeding approaches will enhance the precision and speedy development of improved peanut cultivars for rust resistance.

Substantial efforts have been made in peanut to develop genetic and genomic resources such as identification of diverse parent(s), development of mapping populations, development of molecular markers and identification of Quantitative Trait Loci (QTL), and markers linked to several important traits (Bhat et al. 2012, Pandey et al. 2012a,b, Varshney et al. 2013). Subsequent QTL analysis in two related recombinant inbred line (RIL) populations (TAG $24 \times$ GPBD 4 and TG $26 \times$ GPBD 4) could identify a common genomic region governing rust resistance (Sujay et al. 2012). Two QTLs flanked by GM2009-GM1536 and IPAHM103-GM1954 were detected within this common region on linkage group $\mathrm{AhXV}$, and these two major QTLs explained up to $82.27 \%$ and $82.96 \%$ phenotypic variance (PV), respectively. In addition, a third QTL flanked by GM1536GM2301/GM2079 was detected only in TAG $24 \times$ GPBD 4, which alone could explain $62.35 \%$ of PV. Validation of these QTLs with linked markers for rust resistance will be of great importance in identifying candidate genes as well as for their deployment in molecular breeding for rust resistance in peanut.

Near-isogenic lines (NILs), sharing a common genetic background, but differing by only a small region of the genome (Paterson et al. 1990, Kaeppler et al. 1993), offer a great opportunity for validating the QTLs, in addition to allowing fine mapping and characterization of individual loci (Borevitz and Chory 2004, Brouwer and Clair 2004). NILs are generally developed from advanced backcross lines. NILs differing in nematode resistance have been developed from backcross lines (Holbrook et al. 2008). Alternatively, heterogeneous inbred families (HIFs), developed from selfing and selection scheme (Allard 1960), that segregate only for a small portion of the genome of interest have been utilized as the source of NILs for rust resistance in common bean (Haley et al. 1994) and seed weight in sorghum (Tuinstra et al. 1997). This study reports the development of NILs from HIFs segregating for rust resistance in peanut and validation of previously identified (Sujay et al. 2012) rust resistance QTLs.

\section{Materials and Methods}

Identification of NILs: TAG 24 (Patil et al. 1995) and TG 26 (Kale et al. 1997) are two early-maturing genotypes with high harvest index, high partitioning coefficient and tolerance to bud necrosis, but both are highly susceptible to rust disease. GPBD 4 is a highly resistant variety to rust (Gowda et al. 2002). This variety was derived from the cross KRG 
$1 \times \mathrm{CS} 16$ (ICGV 86855) and is a second-cycle derivative of interspecific hybridization with a desirable combination of early maturity, high yield, high pod growth rate, desirable pod and kernel features with high oil content. Two crosses, TAG $24 \times$ GPBD 4 and TG $26 \times$ GPBD 4 , were made at the University of Agricultural Sciences, Dharwad, India. Generations were advanced by single-seed descent (SSD) method to develop recombinant inbred lines (RILs) for genetic mapping and HIFs for fine mapping/QTL validation. Field screening for rust disease was carried out by inoculating 35 days after sowing (DAS) using infector row technique (Subrahmanyam et al. 1995). Disease scoring was carried out at 70, 80 and 90 DAS according to a modified 9-point scale (Subbarao et al. 1990). Lines segregating for rust resistance in advanced generations like $\mathrm{F}_{5}, \mathrm{~F}_{6}$ and $\mathrm{F}_{7}$ were identified as HIFs in both the crosses. Plants differing in rust resistance in each HIF were harvested separately and evaluated in subsequent generations during 2008 (rainy season), 2009 (rainy season) and 2010 (rainy and summer seasons) under artificial disease epiphytotic conditions. They were also evaluated for pod yield per plant $(\mathrm{g})$, test weight $(\mathrm{g})$ and shelling outturn (\%) during 2010 (summer season) as per the 'Groundnut descriptors' (IBPGR 1992).

Analysis of variance (ANOVA) for various characters was carried out using Windostat, version 8. Pooled analysis of variance was carried out for rust resistance scored at 90 days after sowing (DAS) from the data collected for four seasons. Duncan's multiple range test (DMRT) was carried out for the traits showing significant F using M STAT-C.

\section{Genotyping of parents and NILs}

Genomic DNA was isolated from the parents as well as from plants selected from HIFs following CTAB method (Cuc et al. 2008). HIF-derived plants were checked for the type of allele for the three SSR markers (IPAHM103, GM1536 and GM2301) linked to rust resistance QTLs (Sujay et al. 2012). Touch-down PCR was carried out in a final volume of $20 \mu$ containing $100 \mathrm{ng}$ genomic DNA, 1X PCR buffer, 2 mm dNTPs, 10 pmol of each primer and $1 \mathrm{U}$ of Taq DNA polymerase (New England Biolabs, Ipswich, MA, USA). Amplification was carried out in a mastercycler (Eppendorf, Hamburg, Germany) by setting the conditions for one cycle of predenaturation $\left(94^{\circ} \mathrm{C}\right.$ for $\left.4 \mathrm{~min}\right), 35$ cycles of denaturation $\left(94^{\circ} \mathrm{C}\right.$ for $\left.1 \mathrm{~min}\right)$, annealing (starting from $65^{\circ} \mathrm{C}$ for $30 \mathrm{~s}$ with a decrease of $1^{\circ} \mathrm{C} /$ cycle for the first five cycles) and extension $\left(72^{\circ} \mathrm{C}\right.$ for $\left.1 \mathrm{~min}\right)$. One cycle of final elongation $\left(72^{\circ} \mathrm{C}\right.$ for $\left.10 \mathrm{~min}\right)$ was included before the product was held at $4^{\circ} \mathrm{C}$ for $30 \mathrm{~min}$. The PCR products obtained for GM2301 and IPAHM103 were resolved on 3\% agarose gel by electrophoresis. PCR product of GM1536 was resolved on 4\% polyacrylamide gel electrophoresis (PAGE) using Sequi-Gen (BIO-RAD, Hercules, California, USA) followed by silver staining. The type of allele was scored as susceptible (TAG 24 or TG 26 type) and resistant (GPBD 4 type).

To check the genome similarity between the set of plants selected from each HIF, parental genotypes (TAG 24 vs. GPBD 4 and TG 26 vs. GPBD 4) were screened for polymorphism using A. hypogaea genomic SSR (AHGS) (Shirasawa et al. 2012b), A. hypogaea EST-SSR (AHS) (Koilkonda et al. 2012) and A. hypogaea transposable element (AhTE) markers (Shirasawa et al. 2012a,b). Two possible products of each AhTE marker differing by $\sim 205 \mathrm{bp}$ corresponding to the transposable element (Shirasawa et al. 2012a) were separated on $1.5 \%$ agarose gel. Subsequently, polymorphic AhTE and AHGS markers along with previously tested polymorphic SSR markers (Sujay et al. 2012) covering all the linkage groups were used to genotype the HIFderived plants of both the crosses. The alleles were scored to work out the genome similarity between the plants selected from the same HIF. The same genotypic data were also used to estimate the contribution of the two parents among the HIF-derived plants.

\section{Results}

Families of the advanced generations $\left(\mathrm{F}_{5}, \mathrm{~F}_{6}\right.$ and $\left.\mathrm{F}_{7}\right)$ developed from the two crosses TAG $24 \times$ GPBD 4 and TG $26 \times$ GPBD 4 were evaluated for rust resistance under epiphytotic conditions. Majority of the families bred true, while a few families segregated for rust resistance in $\mathrm{F}_{5: 8}$. Advanced families segregating for rust reaction were identified as heterogeneous inbred families (HIFs). Eleven and ten HIFs were identified in TAG $24 \times$ GPBD 4 and TG $26 \times$ GPBD 4, respectively (Table 1). A set of two or three plants that are either rust resistant (less than score 5) or rust susceptible (more than score 5) was selected from each HIF of both the crosses (Table 1).

Such HIF-derived plants were evaluated for rust resistance during four seasons (rainy season of 2008, 2009, 2010 and summer season of 2010) and productivity traits such as pod yield per plant $(\mathrm{g})$, test weight $(\mathrm{g})$ and shelling outturn (\%) during 2010 (summer season). Analysis of variance indicated a significant variation in rust resistance among the HIF-derived plants of TAG $24 \times$ GPBD 4 and TG $26 \times$ GPBD 4 . Plants selected as resistant and susceptible from each HIF of both the crosses bred true and differed significantly for rust resistance (Table 2). For example, of the two plants selected from HIF 14, 14-1 was rust resistant with a mean disease score of 4.88 and 14-2 was rust susceptible with a score of 6.38 at 90 DAS. In general, although the plants within each set (selected from the same HIF) differed for rust resistance, majority of them did not differ for pod yield per plant (g), test weight (g) and shelling outturn (\%). Hence, the plants within each set were regarded as NILs.

Further, HIF-derived NILs were genotyped using the rust-resistance-linked markers and background markers. The resistant and susceptible alleles for three SSR (IPAHM103, GM1536 and GM2301) loci linked to three major QTLs within the same genomic region on linkage group AhXV governing rust resistance were scored. In general, rust-resistant NILs across the crosses showed resistant (GPBD 4 type) allele for IPAHM103, GM1536 and GM2301 (Fig. 1). Contrastingly, rust-susceptible NILs showed susceptible (TAG 24 or TG 26 type) alleles, indicating that NILs extracted from each HIF differed for the genomic region harbouring rust resistance. A strong cosegregation was found between the type of allele at the three marker loci and the reaction to rust among the NILs. Perfect cosegregation was found among the NILs of nine HIFs (of total 11) in TAG $24 \times$ GPBD 4 and seven HIFs (of total 10) in TG $26 \times$ GPBD 4

Table 1: Heterogeneous inbred families and near-isogenic lines identified for rust resistance among the two crosses of peanut

\begin{tabular}{lcccccc}
\hline \multicolumn{2}{l}{ TAG $24 \times$ GPBD 4} & & \multicolumn{2}{l}{ TG $26 \times$ GPBD 4} \\
\cline { 1 - 2 } \cline { 5 - 6 } SN & HIF & \multicolumn{1}{c}{ NILs } & & SN & HIF & \multicolumn{1}{c}{ NILs } \\
\hline 1 & 9 & $9-1,9-2,9-3$ & & 1 & 1 & $1-1,1-2$ \\
2 & 14 & $14-1,14-1$ & & 2 & 7 & $7-1,7-2$ \\
3 & 47 & $47-1,47-2$ & & 3 & 46 & $46-1,46-2,46-3$ \\
4 & 50 & $50-1,50-2$ & & 4 & 53 & $53-1,53-2$ \\
5 & 60 & $60-1,60-2,60-3$ & & 5 & 58 & $58-1,58-2$ \\
6 & 64 & $64-1,64-2$ & & 6 & 79 & $79-1,79-2,79-3$ \\
7 & 77 & $77-1,77-2$ & & 7 & 138 & $138-1,138-2$ \\
8 & 83 & $83-1,83-2$ & & 8 & 156 & $156-1,156-2$ \\
9 & 89 & $89-1,89-2$ & & 9 & 162 & $162-1,162-2$ \\
10 & 101 & $101-1,101-2$ & & 10 & 167 & $167-1,167-2$ \\
11 & 116 & $116-1,116-2$ & & & \\
\hline
\end{tabular}


Table 2: Performance of the NILs from the two crosses of peanut for productivity traits and rust resistance

\begin{tabular}{|c|c|c|c|c|c|c|c|c|c|}
\hline \multicolumn{5}{|c|}{ TAG $24 \times$ GPBD 4} & \multicolumn{5}{|c|}{ TG $26 \times$ GPBD 4} \\
\hline NILs & $\begin{array}{c}\text { Pod yield } \\
\text { per plant }(\mathrm{g})\end{array}$ & $\begin{array}{c}\text { Test } \\
\text { wt. (g) }\end{array}$ & $\begin{array}{c}\text { Shelling } \\
\text { outturn }(\%)\end{array}$ & $\begin{array}{c}\text { Rust } \\
(90 \text { DAS })^{2}\end{array}$ & NILs & $\begin{array}{c}\text { Pod yield } \\
\text { per plant }(\mathrm{g})\end{array}$ & $\begin{array}{c}\text { Test } \\
\text { wt. (g) }\end{array}$ & $\begin{array}{c}\text { Shelling } \\
\text { outturn }(\%)\end{array}$ & $\begin{array}{c}\text { Rust } \\
(90 \text { DAS })^{2}\end{array}$ \\
\hline $9-1$ & 13.51 & 45.00 & 65.25 & $6.38^{\mathrm{abc}}$ & $1-1$ & 10.60 & $42.00^{\mathrm{bcd}}$ & 61.75 & $4.38^{\mathrm{e}}$ \\
\hline $9-2$ & 10.55 & 47.00 & 69.25 & $4.38^{\mathrm{f}}$ & $1-2$ & 12.27 & $37.50^{\mathrm{de}}$ & 69.00 & $7.13^{\mathrm{b}}$ \\
\hline $9-3$ & 10.39 & 41.00 & 71.50 & $6.5^{\mathrm{ab}}$ & $7-1$ & 10.80 & $49.00^{\mathrm{ab}}$ & 68.00 & $6.13^{\mathrm{c}}$ \\
\hline $14-1$ & 16.90 & 40.50 & 62.50 & $4.88^{\mathrm{ef}}$ & $7-2$ & 12.00 & $39.50^{\text {cde }}$ & 70.00 & $4.13^{\mathrm{e}}$ \\
\hline $14-2$ & 17.51 & 47.25 & 64.75 & $6.38^{\mathrm{abc}}$ & $46-1$ & 14.17 & $51.50^{\mathrm{a}}$ & 74.00 & $6.50^{\mathrm{c}}$ \\
\hline $50-1$ & 15.09 & 48.50 & 73.50 & $5.88^{\mathrm{bcd}}$ & $46-2$ & 15.68 & $34.75^{\mathrm{e}}$ & 71.75 & $7.75^{\mathrm{a}}$ \\
\hline $50-2$ & 11.86 & 48.00 & 77.25 & $4.63^{\mathrm{f}}$ & $46-3$ & 15.46 & $44.50^{\mathrm{abcd}}$ & 72.00 & $4.88^{\mathrm{d}}$ \\
\hline $60-1$ & 16.23 & 44.00 & 71.50 & $6.63^{\mathrm{a}}$ & $53-1$ & 15.12 & $45.50^{\mathrm{abc}}$ & 75.25 & $4.38^{\mathrm{e}}$ \\
\hline $60-2$ & 16.88 & 44.00 & 72.00 & $6.63^{\mathrm{a}}$ & $53-2$ & 15.49 & $46.00^{a b c}$ & 71.75 & $6.19^{c}$ \\
\hline $60-3$ & 15.57 & 46.00 & 74.50 & $4.38^{\mathrm{f}}$ & & & & & \\
\hline $77-1$ & 11.83 & 36.50 & 67.00 & $4.63^{\mathrm{f}}$ & & & & & \\
\hline $77-2$ & 15.02 & 37.50 & 66.75 & $6.88^{\mathrm{a}}$ & & & & & \\
\hline $83-1$ & 11.25 & 34.00 & 67.50 & $4.63^{\mathrm{f}}$ & & & & & \\
\hline $83-2$ & 9.03 & 44.50 & 69.00 & $5.38^{\mathrm{de}}$ & & & & & \\
\hline $89-1$ & 13.09 & 40.00 & 76.00 & $4.5^{\mathrm{f}}$ & & & & & \\
\hline $89-2$ & 15.34 & 38.00 & 74.25 & $6.25^{\mathrm{abc}}$ & & & & & \\
\hline $101-1$ & 14.68 & 41.00 & 68.50 & $4.5^{\mathrm{f}}$ & & & & & \\
\hline $101-2$ & 18.12 & 43.00 & 72.25 & $6.25^{\mathrm{abc}}$ & & & & & \\
\hline $116-1$ & 18.60 & 46.25 & 66.50 & $4.88^{\mathrm{ef}}$ & & & & & \\
\hline $116-2$ & 17.79 & 38.00 & 68.00 & $5.75^{\mathrm{cd}}$ & & & & & \\
\hline CV $(\%)$ & 25.36 & 9.92 & 8.73 & 10.27 & & 12.05 & 6.60 & 12.61 & 10.14 \\
\hline $\operatorname{LSD}(0.05)^{1}$ & 6.24 & - & - & 1.68 & & - & 6.60 & - & 1.88 \\
\hline
\end{tabular}

${ }^{1} \mathrm{LSD}$ is calculated when $\mathrm{F}$ is significant.

${ }^{2}$ Values significantly different at $P<0.05$ are indicated by different letters.

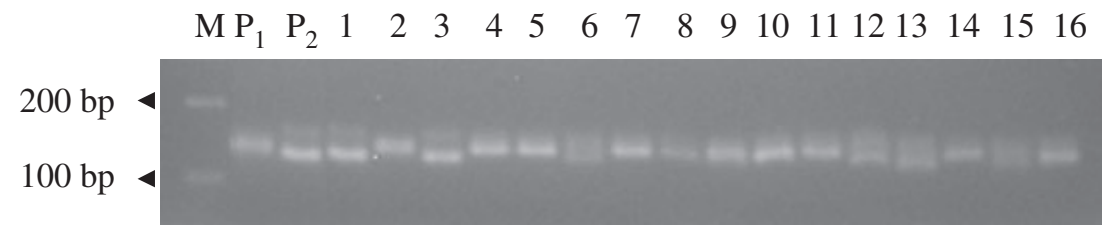

Fig. 1: Contrasting alleles at GM2301 locus among the NILs and parents of TAG $24 \times$ GPBD 4 (M: 100-bp DNA ladder, $\mathrm{P}_{1}$ : TAG 24; $\mathrm{P}_{2}$ : GPBD 4, $1: 14-1,2: 14-2,3: 77-1,4: 77-2,5: 9-1,6: 9-2,7: 9-3,8: 50-1,9: 50-2,10: 60-1,11: 60-2,12: 60-3,13: 89-1,14: 89-2,15: 101-1$ and 16: 101-2)

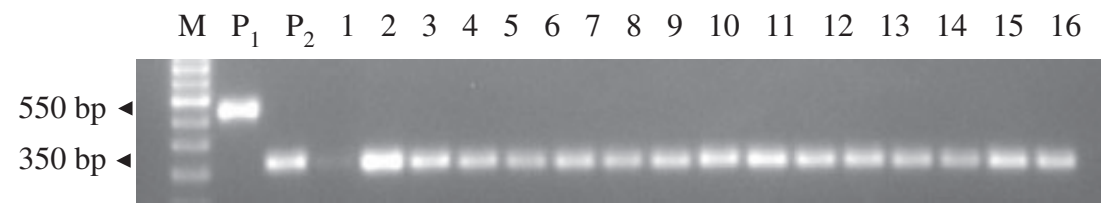

Fig. 2: Type of alleles at a transposon marker (AhTE0268) locus among the NILs and parents of TAG $24 \times$ GPBD 4 (M: 100-bp DNA ladder, $\mathrm{P}_{1}$ : TAG 24; $\mathrm{P}_{2}$ : GPBD 4, 1: 14-1, 2: 14-2, 3: 77-1, 4: 77-2, 5: 9-1, 6: 9-2, 7: 9-3, 8: 50-1, 9: 50-2, 10: 60-1, 11: 60-2, 12: 60-3, 13: 89-1, 14: 89-2, 15: 101-1 and 16: 101-2)

Extent of similarity for other genomic regions was checked among the NILs of nine and selected four HIFs of TAG $24 \times$ GPBD 4 and TG $26 \times$ GPBD 4, respectively. Rust-resistant (GPBD 4) and rust-susceptible (TAG 24 and TG 26) parents were screened with 1079 (AHGS), 470 (AHS) and 405 (AhTE) markers to identify the polymorphic markers. In total, 79 and 163 were polymorphic between TAG 24 vs. GPBD 4 and TG 26 vs. GPBD 4, respectively. In addition, previously identified 89 polymorphic SSR markers were also employed for genotyping the NILs. These polymorphic markers covered all the linkage groups of peanut genome with number of markers per linkage group ranging from 2 (A02) to 14 (A03) in TAG $24 \times$ GPBD 4 , while 6 (B10) to 22 (A03) in TG $26 \times$ GPBD 4 based on consensus maps (Gautami et al. 2012, Shirasawa et al. 2013). The extent of similarity (indicated by monomorphic markers) ranged from $51.7 \%$ (among the NILs of HIF 77) to $86.4 \%$ (among the NILs of HIF 14) in TAG $24 \times$ GPBD 4. Similarly, it varied from $54.8 \%$ (among the plants of HIFs 1) to $83.1 \%$ (among the NILs of HIF 53) in TG $26 \times$ GPBD 4 (Table 3).

An effort was also made to check the relative representation of the two parental genomes among the NILs using the background markers. In general, the average representation of TAG 24-type alleles was more with a range of $41.1-62.7 \%$ among the NILs of TAG $24 \times$ GPBD 4 . Likewise, the average number of TG 26 type of alleles was more with a range of 41.9-64.4\% among the NILs of TG $26 \times$ GPBD 4 , indicating a wide range of recombination events among the HIFs (Table 4). But it was interesting to note that the phenotype of the NILs with regard to rust resistance was not influenced by the background genome of either of the parents. 
Table 3: Genome similarity between the pair of NILs derived from the HIFs of the two crosses of peanut

\begin{tabular}{|c|c|c|c|c|c|}
\hline \multicolumn{3}{|c|}{ TAG $24 \times$ GPBD 4} & \multicolumn{3}{|c|}{ TG $26 \times$ GPBD 4} \\
\hline Pair of NILs & Total number of markers & Monomorphic markers & Pair of NILs & Total number of markers & Monomorphic markers \\
\hline $9-1: 9-2$ & 162 & $127(78.4)$ & $1-1: 1-2$ & 228 & $125(54.8)$ \\
\hline $9-2: 9-3$ & 162 & $128(79.0)$ & 7-1:7-2 & 187 & $112(59.9)$ \\
\hline $9-1: 9-3$ & 161 & $133(82.6)$ & $46-1: 46-2$ & 224 & $149(66.5)$ \\
\hline $14-1: 14-2$ & 132 & $114(86.4)$ & $46-2: 46-3$ & 216 & $131(60.7)$ \\
\hline $50-1: 50-2$ & 162 & $99(61.1)$ & $46-1: 46-3$ & 209 & $163(80.0)$ \\
\hline $60-1: 60-2$ & 151 & $90(59.6)$ & $53-1: 53-2$ & 219 & $182(83.1)$ \\
\hline $60-2: 60-3$ & 145 & $95(65.5)$ & & & \\
\hline $60-1: 60-3$ & 150 & $88(58.7)$ & & & \\
\hline 77-1: 77-2 & 151 & $78(51.7)$ & & & \\
\hline $83-1: 83-2$ & 140 & $77(55.0)$ & & & \\
\hline $89-1: 89-2$ & 135 & $97(71.9)$ & & & \\
\hline $101-1: 101-2$ & 138 & $91(65.9)$ & & & \\
\hline $116-1: 116-2$ & 133 & $87(65.4)$ & & & \\
\hline
\end{tabular}

Values in the parentheses indicate the percentage similarity.

Table 4: Representation of the parental alleles among the NILs of the two crosses of peanut

\begin{tabular}{|c|c|c|c|c|c|}
\hline \multicolumn{3}{|c|}{ TAG $24 \times$ GPBD 4} & \multicolumn{3}{|c|}{ TG $26 \times$ GPBD 4} \\
\hline NIL & TAG 24 & GPBD 4 & NIL & TG 26 & GPBD 4 \\
\hline $9-1$ & $78(48.2)$ & $84(51.9)$ & $1-1$ & $145(60.7)$ & $94(39.3)$ \\
\hline $9-2$ & $87(53.1)$ & $77(47.0)$ & $1-2$ & $111(46.8)$ & $126(53.2)$ \\
\hline $9-3$ & $84(51.95$ & $78(48.2)$ & $7-1$ & $132(64.4)$ & $73(35.6)$ \\
\hline $14-1$ & $82(61.7)$ & $51(38.4)$ & $7-2$ & $96(42.3)$ & $131(57.7)$ \\
\hline $14-2$ & $93(58.9)$ & $65(41.1)$ & $46-1$ & $104(45.2)$ & $126(54.8)$ \\
\hline $50-1$ & $74(44.6)$ & $92(55.4)$ & $46-2$ & $154(64.2)$ & $86(35.8)$ \\
\hline $50-2$ & $91(55.5)$ & $73(44.5)$ & $46-3$ & $93(41.9)$ & $129(58.1)$ \\
\hline $60-1$ & $71(43.9)$ & $91(56.2)$ & $53-1$ & $117(48.8)$ & $123(51.3)$ \\
\hline $60-2$ & $81(52.6)$ & $73(47.4)$ & $53-2$ & $115(51.3)$ & $109(48.7)$ \\
\hline $60-3$ & $87(56.9)$ & $66(43.1)$ & & & \\
\hline $77-1$ & $91(57.2)$ & $68(42.8)$ & & & \\
\hline $77-2$ & $78(49.7)$ & $79(50.3)$ & & & \\
\hline $83-1$ & $75(47.2)$ & $84(52.8)$ & & & \\
\hline $83-2$ & $74(51.0)$ & $71(49.0)$ & & & \\
\hline $89-1$ & $96(60.8)$ & $62(39.2)$ & & & \\
\hline $89-2$ & $75(52.8)$ & $67(47.2)$ & & & \\
\hline $101-1$ & $91(60.7)$ & $59(39.3)$ & & & \\
\hline $101-2$ & $62(41.1)$ & 89 (58.9) & & & \\
\hline $116-1$ & $71(46.4)$ & $82(53.6)$ & & & \\
\hline $116-2$ & $89(62.7)$ & $53(37.3)$ & & & \\
\hline
\end{tabular}

Values in the parentheses indicate the percentage.

\section{Discussion}

Heterogeneous inbred families (HIFs) are developed through selfing and selection scheme (Allard 1960). As HIFs represent advanced inbred lines, they segregate for only a small region within the genome. Use of molecular markers allows faster identification of HIFs that segregate for the marker(s) at the genomic region of interest. Within each HIF, the plants that differ for the marker at the genomic region of the interest or for the phenotype are selected as the near-isogenic lines (NILs). HIFs offer a timeand cost-effective source of NILs as compared to backcross lines. HIF-derived NILs have been used for validating the QTLs (Loudet et al. 2005, Diaz et al. 2006, Bai et al. 2010, Liu et al. 2011, Ma et al. 2012, Tuyen et al. 2013) and narrowing down the genomic region harbouring the QTL (Hu et al. 1997, Yamanaka et al. 2005, Coles 2009, Liu et al. 2009, 2011).

This study reports the development of NILs from HIFs that segregate for rust resistance and using them for validating the rust resistance QTLs in peanut. Advanced generations of two crosses, TAG $24 \times$ GPBD 4 and TG $26 \times$ GPBD 4 involving the parents differing in rust resistance, consisted of a few families segregating for rust resistance. In total, 11 and 10 such heterogeneous inbred families (HIFs) were identified in $\mathrm{F}_{5: 8}$ from TAG $24 \times$ GPBD 4 and TG $26 \times$ GPBD 4, respectively. From each HIF, rust-resistant (less than score 5) and rust-susceptible (more than score 5) plants were selected in both the crosses. Field evaluation of HIF-derived plants during 2008-2010 indicated that the plants differed significantly for rust resistance but not in general for productivity traits such as pod yield per plant (g), test weight (g) and shelling outturn (\%). Such plants originating from the same HIF and segregating only for rust resistance but not for other traits were selected as NILs as a genetic resource for further genetic studies.

Availability of DNA markers allows ascertaining the genomic regions that either differ or not (isogenic) between the NILs. For this purpose, IPAHM103, GM1536 and GM2301 SSR markers each linked to the three different QTLs at a single genomic region (20.6 cM on linkage group $\mathrm{AhXV}$ ) harbouring rust resistance (Sujay et al. 2012) were selected. NILs belonging to the same HIF differed in the type allele at the three SSR loci. The set of NILs derived from nine and four HIFs of TAG $24 \times$ GPBD 4 and TG $26 \times$ GPBD 4, respectively, was then tested for background genome similarity after parental survey with a large number of transposable element markers and SSR markers covering complete peanut genome based on published consensus genetic maps (Gautami et al. 2012, Shirasawa et al. 2013). Genotyping with 168 and 252 polymorphic markers in TAG $24 \times$ GPBD 4 and TG $26 \times$ GPBD 4 , respectively, indicated a considerably high loci similarity among the NILs belonging to the same set. NILs (14-1 and 14-2) derived from HIF 14 showed the highest genome similarity of $86.4 \%$ among those selected in TAG $24 \times$ GPBD 4 . The same was $83.1 \%$ among the 53-1 and 53-2 NILs of HIF 53 in TG $26 \times$ GPBD 4 . Therefore, the plants selected from each HIF could be regarded as the NILs because they phenotypically differed only for rust resistance but not for productivity traits. In addition, genotypically, these NILs carried contrasting alleles only at the three SSR loci linked to rust resistance while retaining the identical alleles at majority of other loci.

To date, HIF-derived NILs have been reported from rice (Kobayashi et al. 2006), sorghum (Tuinstra et al. 1997, Goldsbrough et al. 1998), wheat (Hu et al. 1997), maize (Coles 2009), 
barley (Nduulu et al. 2002), Arabidopsis (Bikard et al. 2009) and soybean (Ikeda et al. 2009). Although development of NILs differing in resistance to peanut root knot nematode has been reported by backcross breeding approach (Holbrook et al. 2008), this is the first report on developing NILs from HIFs in peanut.

In this study, the QTLs governing rust resistance (Sujay et al. 2012) were validated by determining the type of allele at linked markers and the phenotype. Largely, rust-resistant NILs carried resistant (GPBD 4-type) allele for all the three markers, while rust-susceptible NILs carried susceptible (TAG 24 or TG 26type) allele depending on the cross. Such a cosegregation between the type of allele and the phenotype was to the extent of $81.8 \%$ in TAG $24 \times$ GPBD 4 and $70.0 \%$ in TG $26 \times$ GPBD 4 , indicating a strong association between the QTLs and rust resistance.

Near-isogenic lines (NILs) derived from HIFs in comparison with backcross-derived NILs have a unique advantage of ascertaining the expression of a specific locus under different genomic contexts as the NILs (across the HIFs) represent an array of recombination events. Such a situation would also enable ascertaining epistatic interactions and degree of penetrance for the genomic region in question (Tuinstra et al. 1997). In turn, this also gives the advantage of selecting the ideal genetic background that gives maximum expression of the QTL. This is mainly due to the fact that HIF-derived NILs, unlike backcross-derived NILs, do not bear strict resemblance to the recurrent parent (Haley et al. 1994). Hence, an effort was made in the present study to determine the relative representation of the two parental genomes among the NILs as a possible measure of recombination.

In general, alleles from the female parents were more frequent than those of male parents in both the crosses. Average number of alleles from TAG 24 ranged from 41.1 to $62.7 \%$ among the NILs of TAG $24 \times$ GPBD 4 . Likewise, the average number of TG 26 type of alleles ranged from 41.9 to $64.4 \%$ among the NILs of TG $26 \times$ GPBD 4 . This wide range of allele representation is the indicative of diverse recombination events among the HIFs and thereby among the NILs. Hence, the NILs identified in this study with varied recombination events could be used in analysing the expression of the rust resistance QTLs in terms of their epistatic interactions and penetrance. Currently, these NILs are being employed for fine mapping and expression analysis of rust resistance QTLs. NILs are also being registered by depositing the seeds at National Bureau of Plant Genetic Resources, New Delhi.

\section{References}

Allard, R. W., 1960: Principles of Plant Breeding. John Wiley, New York.

Bai, X., L. Luo, W. Yan, M. R. Kovi, W. Zhan, and Y. Xing, 2010: Genetic dissection of rice grain shape using a recombinant inbred line population derived from two contrasting parents and fine mapping a pleiotropic quantitative trait locus qGL 7. BMC Genet. 11, 16.

Bhat, R. S., V. Sujay, G. Mukri, Y. P. Khedikar, C. Sarvamangala, S. B. Yeri, S. S. Jadhav, S. B. Pujer, R. Narasimhulu, Varshakumari, T. P. M. Azharudheen, R. K. Varshney, H. L. Nadaf, and M. V. C. Gowda, 2012: Utility of peanut mapping populations developed at UAS Dharwad, India VI International Conference on Legume Genetics and Genomics (ICLGG), Hyderabad Marriott Hotel \& Convention Centre Hyderabad, India.

Bikard, D., D. Patel, C. Le Metté, V. Giorgi, C. Camilleri, M. J. Bennett, and O. Loudet, 2009: Divergent evolution of duplicate genes leads to genetic incompatibilities within A. thaliana. Science 323, 623-626.
Borevitz, J. O., and J. Chory, 2004: Genomics tools for QTL analysis and gene discovery. Curr. Opin. Plant Biol. 7, 132-136.

Bromfield, K., and W. Bailey, 1972: Inheritance of resistance to Puccinia arachidis in peanut. Phytopathology 62, 748.

Brouwer, D., and D. S. Clair, 2004: Fine mapping of three quantitative trait loci for late blight resistance in tomato using near isogenic lines (NILs) and sub-NILs. Theor. Appl. Genet. 108, 628-638.

Coles, N. D., 2009: The Genetic Architecture of Maize Photoperiod Sensitivity as Revealed by Recombinant Inbred Line, Backcross, and Heterogeneous Inbred Family Populations. North Carolina State University, Raleigh, NC.

Cuc, L. M., E. S. Mace, J. H. Crouch, V. D. Quang, T. D. Long, and R. K. Varshney, 2008: Isolation and characterization of novel microsatellite markers and their application for diversity assessment in cultivated groundnut (Arachis hypogaea). BMC Plant Biol. $8,55$.

Diaz, C., V. Saliba-Colombani, O. Loudet, P. Belluomo, L. Moreau, F. Daniel-Vedele, J.-F. Morot-Gaudry, and C. Masclaux-Daubresse, 2006: Leaf yellowing and anthocyanin accumulation are two genetically independent strategies in response to nitrogen limitation in Arabidopsis thaliana. Plant Cell Physiol. 47, 74-83.

Gautami, B., D. Fonceka, M. K. Pandey, M. C. Moretzsohn, V. Sujay, H. Qin, Y. Hong, I. Faye, X. Chen, A. BhanuPrakash, T. M. Shah, M. V. Gowda, S. N. Nigam, X. Liang, D. A. Hoisington, B. Guo, D. J. Bertioli, J. F. Rami, and R. K. Varshney, 2012: An international reference consensus genetic map with 897 marker loci based on 11 mapping populations for tetraploid groundnut (Arachis hypogaea L.). PLoS ONE 7, e41213.

Goldsbrough, P., G. Ejeta, and M. Tuinstra, 1998: Evaluation of nearisogenic sorghum lines contrasting for QTL markers associated with drought tolerance. Crop Sci. 38, 835-842.

Gowda, M., B. Motagi, G. Naidu, S. Diddimani, and R. Sheshagiri, 2002: GPBD 4: a spanish bunch groundnut genotype resistant to rust and late leaf spot. Int. Arachis Newslet. 22, 29-32.

Haley, S. D., L. K. Afanador, P. N. Miklas, J. R. Stavely, and J. D. Kelly, 1994: Heterogeneous inbred populations are useful as sources of near-isogenic lines for RAPD marker localization. Theor. Appl. Genet. 88, 337-342.

Holbrook, C. C., P. Timper, W. Dong, C. K. Kvien, and A. K. Culbreath, 2008: Development of near-isogenic peanut lines with and without resistance to the peanut root-knot nematode. Crop Sci. 48, 194-198.

Hu, X. Y., H. W. Ohm, and I. Dweikat, 1997: Identification of RAPD markers linked to the gene Pm 1 for resistance to powdery mildew in wheat. Theor. Appl. Genet. 94, 832-840.

IBPGR, 1992: Descriptors for Groundnut International Board for plant genetic resources, Rome, Italy. International crops research Institute for the semi-arid tropics, Patancheru, India.

Ikeda, T., S. Ohnishi, M. Senda, T. Miyoshi, M. Ishimoto, K. Kitamura, and H. Funatsuki, 2009: A novel major quantitative trait locus controlling seed development at low temperature in soybean (Glycine max). Theor. Appl. Genet. 118, 1477-1488.

Kaeppler, S. M., R. L. Phillips, and T. S. Kim, 1993: Use of nearisogenic lines derived by backcrossing or selfing to map qualitative traits. Theor. Appl. Genet. 87, 233-237.

Kale, D., C. Mouli, G. Murty, and M. Rao, 1997: Development of a new groundnut variety, TG-26 by using induced mutations in cross breeding. Mutat. Breed. Newsl. 43, 25-27.

Kobayashi, S., E. Araki, M. Osaki, G. S. Khush, and Y. Fukuta, 2006: Localization, validation and characterization of plant-type QTLs on chromosomes 4 and 6 in rice (Oryza sativa L.). Field Crops Res. 96, $106-112$.

Koilkonda, P., S. Sato, S. Tabata, K. Shirasawa, H. Hirakawa, H. Sakai, S. Sasamoto, A. Watanabe, T. Wada, Y. Kishida, H. Tsuruoka, T. Fujishiro, M. Yamada, M. Kohara, S. Suzuki, M. Hasegawa, H. Kiyoshima, and S. Isobe, 2012: Large-scale development of expressed sequence tag-derived simple sequence repeat markers and diversity analysis in Arachis spp. Mol. Breed 30, 125-138. 
Liu, T., D. Mao, S. Zhang, C. Xu, and Y. Xing, 2009: Fine mapping SPP1, a QTL controlling the number of spikelets per panicle, to a BAC clone in rice (Oryza sativa). Theor. Appl. Genet. 118, 1509-1517.

Liu, Y., X. Y. Zhu, S. Zhang, M. Bernardo, J. Edwards, D. W. Galbraith, J. Leach, G. Zhang, B. Liu, and H. Leung, 2011: Dissecting quantitative resistance against blast disease using heterogeneous inbred family lines in rice. Theor. Appl. Genet. 122, 341-353.

Loudet, O., V. Gaudon, A. Trubuil, and F. Daniel-Vedele, 2005: Quantitative trait loci controlling root growth and architecture in Arabidopsis thaliana confirmed by heterogeneous inbred family. Theor. Appl. Genet. 110, 742-753.

Ma, J., G. Yan, and C. Liu, 2012: Development of near-isogenic lines for a major QTL on 3BL conferring Fusarium crown rot resistance in hexaploid wheat. Euphytica 183, 147-152.

Nduulu, L., A. Mesfin, G. Muehlbauer, and K. Smith, 2002: Effect of Chevron alleles at two Fusarium head blight resistance QTL determined using near-isogenic lines National Fusarium Head Blight Forum, 35-38. Erlanger, KY.

Pandey, M., E. Monyo, P. Ozias-Akins, X. Liang, P. Guimarães, S. Nigam, H. Upadhyaya, P. Janila, X. Zhang, and B. Guo, 2012a: Advances in Arachis genomics for peanut improvement. Biotechnol. Adv. 30, 639-651.

Pandey, M. K., B. Gautami, T. Jayakumar, M. Sriswathi, H. D. Upadhyaya, M. V. C. Gowda, T. Radhakrishnan, D. J. Bertioli, S. J. Knapp, D. R. Cook, and R. K. Varshney, 2012b: Highly informative genic and genomic SSR markers to facilitate molecular breeding in cultivated groundnut (Arachis hypogaea). Plant Breed 131, 139-147.

Paramasivam, K., M. Jayasekhar, R. Rajasekharan, and P. Veerabadhiran, 1990: Inheritance of rust resistance in groundnut (Arachis hypogaea L.). Madras Agric. J. 77, 50-52.

Paterson, A. H., J. W. DeVerna, B. Lanini, and S. D. Tanksley, 1990: Fine mapping of quantitative trait loci using selected overlapping recombinant chromosomes, in an interspecies cross of tomato. Genetics 124, 735 .

Patil, S., D. Kale, S. Deshmukh, G. Fulzele, and B. Weginwar, 1995: Semi-dwarf, early maturing and high yielding new groundnut variety, TAG-24. J. Oilseed Res. 12, 254-257.

Shirasawa, K., H. Hirakawa, S. Tabata, M. Hasegawa, H. Kiyoshima, S. Suzuki, S. Sasamoto, A. Watanabe, T. Fujishiro, and S. Isobe, 2012a: Characterization of active miniature inverted-repeat transposable elements in the peanut genome. Theor. Appl. Genet. 124, 1429-38.

Shirasawa, K., P. Koilkonda, K. Aoki, H. Hirakawa, S. Tabata, M. Watanabe, M. Hasegawa, H. Kiyoshima, S. Suzuki, C. Kuwata, Y Naito, T. Kuboyama, A. Nakaya, S. Sasamoto, A. Watanabe, M. Kato, K. Kawashima, Y. Kishida, M. Kohara, A. Kurabayashi, C. Takahashi, H. Tsuruoka, T. Wada, and S. Isobe, 2012b: In silico polymorphism analysis for the development of simple sequence repeat and transposon markers and construction of linkage map in cultivated peanut. BMC Plant Biol. 12, 80.

Shirasawa, K., D. J. Bertioli, R. K. Varshney, M. C. Moretzsohn, S. C. Leal-Bertioli, M. Thudi, M. K. Pandey, J. F. Rami, D. Fonceka, M. V. Gowda, H. Qin, B. Guo, Y. Hong, X. Liang, H. Hirakawa, S. Tabata, and S. Isobe, 2013: Integrated consensus map of cultivated peanut and wild relatives reveals structures of the A and B genomes of Arachis and divergence of the legume genomes. DNA Res. 20, 173-184.

Subbarao, P. V., P. Subramanyam, and P. M. Reddy, 1990: A modified nine points diseases scale for assessment of rust and late leaf spot of groundnut Second International Congress of French Phytopathological Society, 25. French Phyto-Pathological Society, Montpellier, France.

Subrahamanyam, P., D. McDonald, L. J. Reddy, S. N. Nigam, and D. H. Smith, 1993: Origin and utilization of rust resistance in groundnut. In: T. Jacobs, and J. E. Parlevliet (eds), Durability of disease resistance. 147-158, Kluver Academic Publishers, Dordrecht.

Subrahmanyam, P., D. McDonald, F. Waliar, L. J. Reddy, S. N. Nigam, R. W. Gibbons, V. R. Rao, A. K. Singh, S. Pande, P. M. Reddy, and P. V. S. Rao, 1995: Screening methods and sources of resistance to rust and late leaf spot of groundnut. (In Eng. Summaries in En, Fr, Sp, and Pt.). Information Bulletin no. 47. Patancheru 502324, International Crops Research Institute for the Semi-Arid Tropics, Andhra Pradesh, India.

Sujay, V., M. V. C. Gowda, M. K. Pandey, R. S. Bhat, Y. P. Khedikar, H. L. Nadaf, B. Gautami, C. Sarvamangala, S. Lingaraju, T. Radhakrishan, S. J. Knapp, and R. K. Varshney, 2012: QTL analysis and construction of consensus genetic map for foliar disease resistance based on two RIL populations in cultivated groundnut (Arachis hypogaea L.). Mol. Breed 30, 773-788.

Tiwari, S., M. Ghewande, and D. Misra, 1984: Inheritance of resistance to rust and late leaf spot in groundnut (Arachis hypogaea L.). J. Cytol. Genet 19, 97-101.

Tuinstra, M. R., G. Ejeta, and P. B. Goldsbrough, 1997: Heterogeneous inbred family (HIF) analysis: a method for developing near-isogenic lines that differ at quantitative trait loci. Theor. Appl. Genet. 95, 1005 -1011 .

Tuyen, D., H. Zhang, and D. Xu, 2013: Validation and high-resolution mapping of a major quantitative trait locus for alkaline salt tolerance in soybean using residual heterozygous line. Mol. Breed 31, 79-86.

Varshney, R. K., S. M. Mohan, P. M. Gaur, N. Gangarao, M. K. Pandey, A. Bohra, S. L. Sawargaonkar, A. Gorantla, P. K. Kimurto, and P. Janila, 2013: Achievements and prospects of genomics-assisted breeding in three legume crops of the semi-arid tropics. Biotechnol. Adv., http://dx.doi.org/10.1016/j.biotechadv.2013.01.001.

Yamanaka, N., S. Watanabe, K. Toda, M. Hayashi, H. Fuchigami, R. Takahashi, and K. Harada, 2005: Fine mapping of the FT1 locus for soybean flowering time using a residual heterozygous line derived from a recombinant inbred line. Theor. Appl. Genet. 110, 634-639. 